\title{
Positioner and the Procedure for Measuring Spatial Characteristics
}

\author{
Rudolf Drga ${ }^{1}$, Dagmar Janáčová ${ }^{2}$, Rudolf Palenčár ${ }^{3}$, Stanislav Ďuriš ${ }^{3}$ \\ ${ }^{1}$ Faculty of Applied Informatics, Department of Security Engineering, Tomas Bata University in Zlín, 76001 Zlín, nám. T. G. \\ Masaryka 5555, Czech Republic,e-mail: rdrga@utb.cz \\ ${ }^{2}$ Faculty of Applied Informatics, Department of Automation and Control Engineering, Tomas Bata University in Zlin, 76001 \\ Zlín, nám. T. G. Masaryka 5555, Czech Republic, e-mail: janacova@utb.cz \\ ${ }^{3}$ Faculty of Mechanical Engineering, Institute of Automation, Measurements and Applied Informatics, Slovak Technical \\ University, 81243 Bratislava, Nám. Slobody 17, Slovak Republic, email: rudolf.palencar@stuba.sk
}

The present work focuses on the solution of management of measuring spatial characteristics of security detectors using a positioner, a precision manipulator. It deals with program management software in LabView. Graphical programming with subroutines, which are described as virtual instruments, is used. There are published results of measurements of the spatial characteristics of the PIR detector, where it is preferably used as the measuring station.

Keywords: Magnetic measurement, imaging, magnetic susceptibility, calculation, microwave frequencies.

\section{INTRODUCTION}

To ensure correct operation of safety devices that handle electromagnetic signal or wave thermal radiation from space in their vicinity, it is important to know the spatial characteristics of the device. According to this feature, we can specify the maximum range of the device or its sensitivity to a certain distance and direction. For example, Fig.1. shows the characteristics of the fire flame detectors S200 and S300. The detector S200 represents a classic flame detector, which uses a radiation sensor of the flame [7]. It consists of further filter lets through the radiation generated during combustion of a particular material. The detector S300 represents a flame detector, which consists of the sensor array of $16 \times 16$ points, and as shown in the figure, it is characterized by less than $90^{\circ}$ coverage.

Moreover, there is the possibility of determining the position used in the flame space using polar coordinates, and the system then marks this region in the camera image, which is part of the detector, as shown in Fig.2. This is very advantageous in the case that the actual flame emits radiation which is outside the visible spectrum, and thus invisible to the human eye [4]. In this example, it is clear that for use in security technology it is important to exactly determine the spatial characteristics of the particular device, in this case, the flame detector. In the lower part of the figure is a table for the flame range of $0.1 \mathrm{~m}^{2}$ area for various types of burning material. As is evident from the table, the maximum distance of the detected flame is relatively large; it is from $35 \mathrm{~m}$ to $60 \mathrm{~m}$. This can be a relatively large problem for implementing a workplace where we want to measure this characteristic [6].

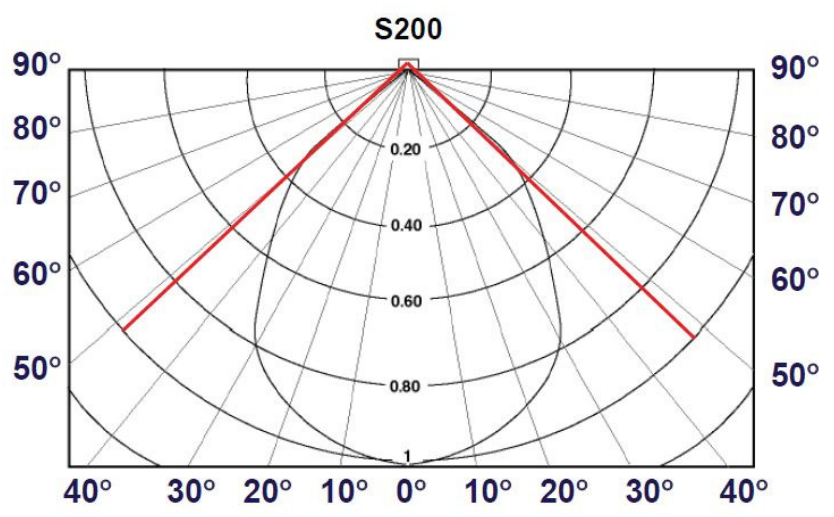

Fig.1. Characteristics of the flame detector types S200 and S300.

\section{METHODS OF MEASUREMENT OF SPATIAL CHARACTERISTICS}

One of the simplest methods how to measure spatial characteristics is to create a workplace whose dimensions correspond to the real ranges of the device, as shown in Fig.3. Shining object 1 is moving in polar coordinates, and after reaching the new position, the impact of radiation occurs on 
the measurement device 2 and performs measurements using measuring instruments 3 [1], [2], [10]. The disadvantage of this solution is the fact that the dimensions of the workplace are large [3], in the case of flame detectors we need to create a grid of lines with an area of $60 \mathrm{~m} \mathrm{x} 40 \mathrm{~m}$ with the fact that characteristics are spatial and must, therefore, reckon with height in the range from $10 \mathrm{~m}$ to $20 \mathrm{~m}$. Another problem is the exact movement of the source of radiation behind the desktop workstation, or the ability to change its height from the floor. In this case, the radiation source moves behind the desktop manually [5]. Another way to move the source of radiation in space is the use of a robot that moves in Cartesian coordinates behind the desktop. In this way, the measurement was performed by PIR [9], [13] detectors in Belgium according to the standard T 014: 2014, as shown in Fig.4.

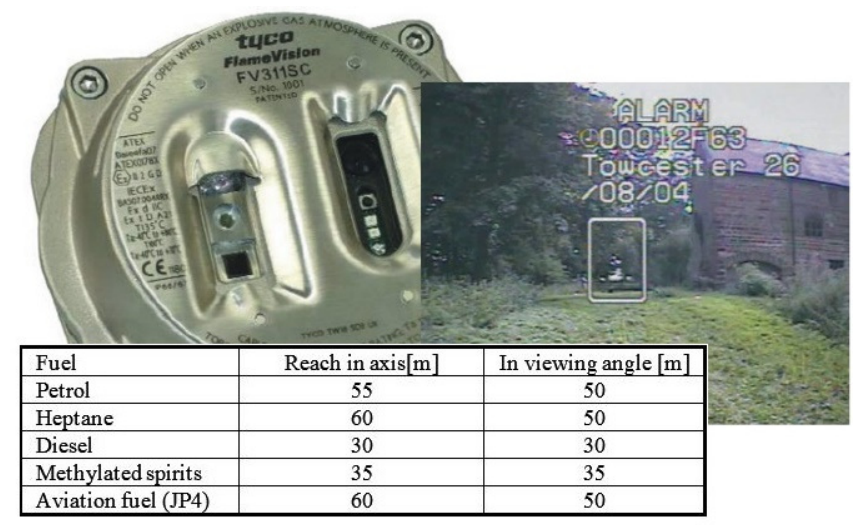

Fig.2. Fire alarm detector S300 and the camera image by specifying the place of burning.

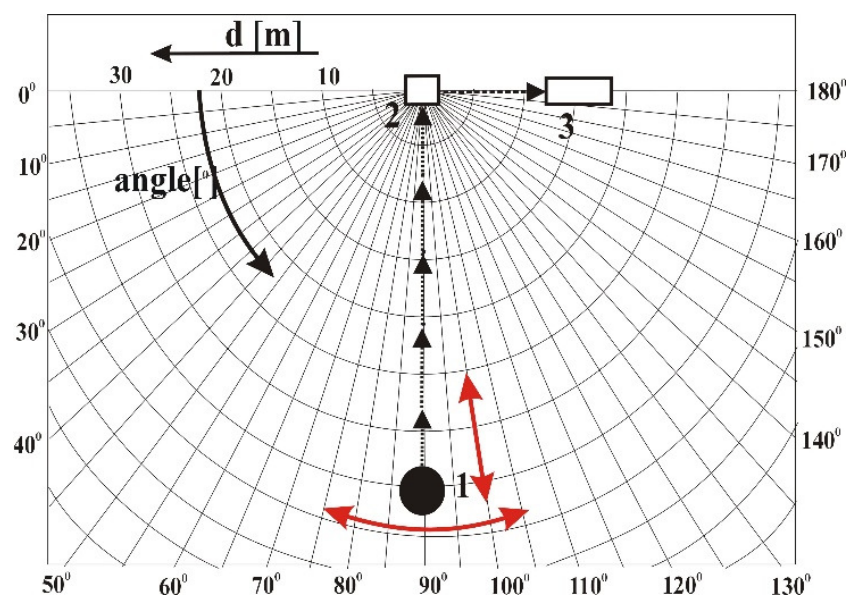

Fig.3. The classical concept of measuring workplace.

Source 1 was located on the chassis, which was moving exactly along the floor of the test room [8]. The chassis has located the source of the radiation, which is represented by a prism warmed to a specific temperature; this rotates around the vertical axis and also around the second axis, which is placed on the chassis, as shown in the figure. Radiation then turns on its MOTION detector, and its response is measured using measuring instruments 3 .

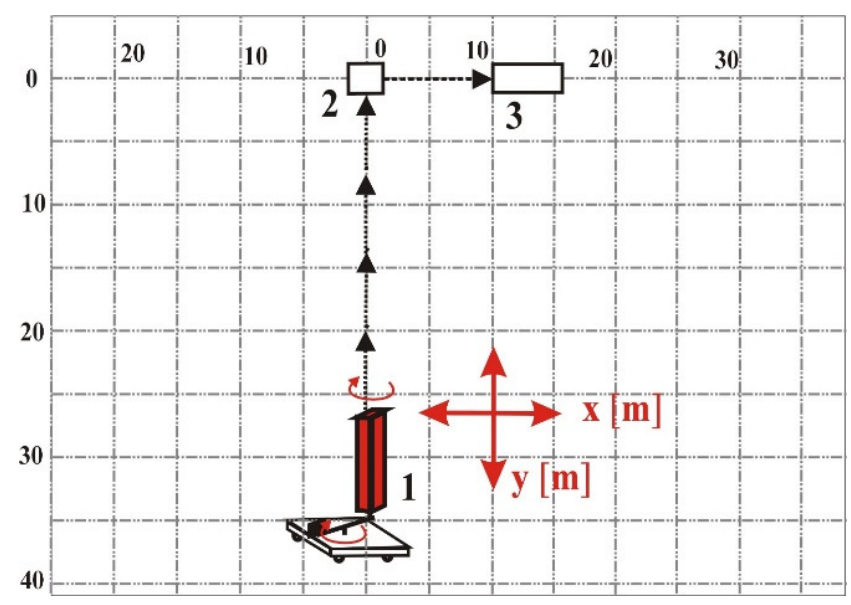

Fig.4. Robotic concept of a measuring workplace.

\section{NEW METHOD FOR MEASURING SPATIAL CHARACTERISTICS}

Because of the reasons referred to in the previous chapter, a workplace was designed, where the function was changed due to the motion of the source of the radiation scanning device. In this case, the source of radiation 1 is static and moving the actual measurement device 2 measuring instruments 3 . The measuring devices 3 are located in its vicinity, as shown in Fig.5. Devices whose characteristic measured is placed on a very accurate multiaxial manipulator 4 are programmatically controlled by special programs for positioning.

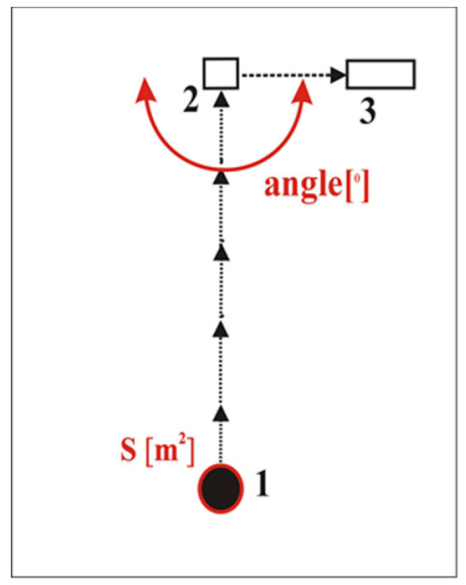

Fig.5. New concept of measuring workplace.

The distance of the source of radiation is simulated, the size of the object, or a broadcast performance [14], [19]. In the case of thermal radiation, the size of the surfaces of the heater is changing.

\section{POSITIONER RESULTS}

The basic part of measuring workplace is a positioner, which is a six-axis manipulator on which is placed a device whose characteristics are measured [12]. A highly accurate motion in all axes is shown in Fig.6.

Movement of the endpoint can be realized using three linear movements and three rotational movements. 


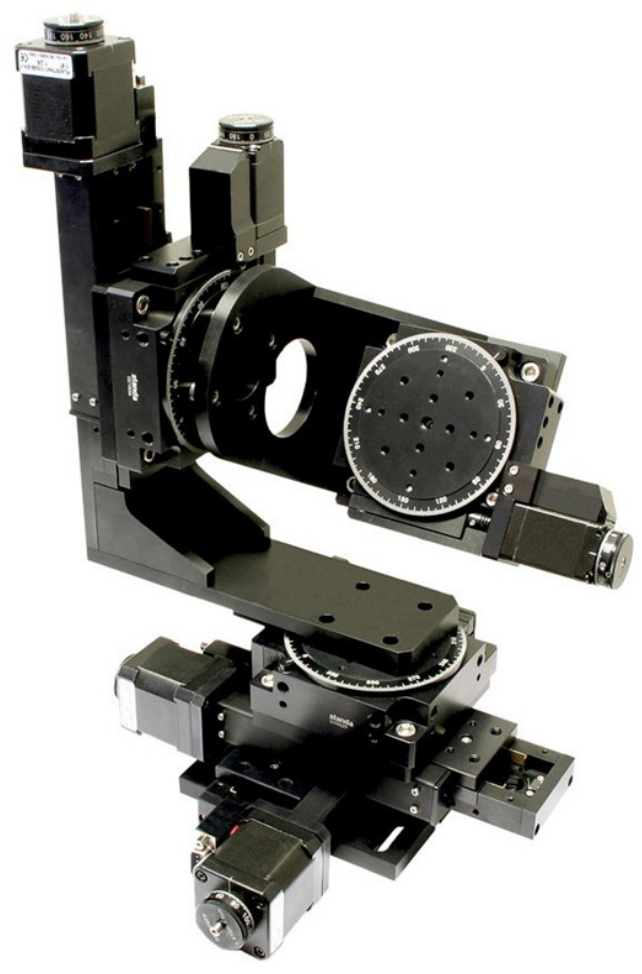

Fig.6. Positioner and its construction.

The total distance of the linear movement is $50 \mathrm{~mm}$ and the drive to overcome it by using 20,000 steps. The number of steps at the rotary motion necessary to rotate by $360^{\circ}$ is 36,000 steps.

The accuracy of motion in each axis is determined by the accuracy of the positioning device and the values shown in Table 1. and Table 2. Basic specifications of the entire device are shown in Table 3.

Table 1. Specifications rotary positioning device.

\begin{tabular}{|l|l|}
\hline Rotation range & $360^{\circ}$ \\
\hline Resolution in full step & $0.6 \mathrm{arcmin}\left(0,01^{\circ}\right)$ \\
\hline Max. rotation speed & $8 \mathrm{ot} / \mathrm{min}$ \\
\hline Backlash & $0 \mu \mathrm{m}$ \\
\hline Wobble & $0.5 \mathrm{arcmin}$ \\
\hline Eccentricity & $10 \mu \mathrm{m}$ \\
\hline Load capacity horizontal & $10 \mathrm{~kg}$ \\
\hline Load capacity vertical & $2 \mathrm{~kg}$ \\
\hline Torque & $1 \mathrm{Nm}$ \\
\hline Weight & $0.65 \mathrm{~kg}$ \\
\hline
\end{tabular}

Table 2. Specifications longitudinal positioning device.

\begin{tabular}{|l|l|}
\hline Range of motion & $50 \mathrm{~mm}$ \\
\hline Resolution in full step & $2.5 \mu \mathrm{m}$ \\
\hline Max. speed & $10 \mathrm{~mm} / \mathrm{sec}$ \\
\hline Load capacity horizontal & $8 \mathrm{~kg}$ \\
\hline Load capacity vertical & $3 \mathrm{~kg}$ \\
\hline Torque & $1 \mathrm{Nm}$ \\
\hline Weight & $1 \mathrm{~kg}$ \\
\hline
\end{tabular}

Table 3. Basic accuracy of the positioner.

\begin{tabular}{|l|l|}
\hline Precision full-step shift & $2.5 \mu \mathrm{m}$ \\
\hline Precision full step rotation & $0.01^{\circ}$ \\
\hline Will feed & $0.6 \mu \mathrm{m}$ \\
\hline Will rotation & $0.5 \mathrm{arcmin}$ \\
\hline $\begin{array}{l}\text { Repeatability of positioning } \\
\text { the shift-way }\end{array}$ & $0.6 \mu \mathrm{m}$ \\
\hline $\begin{array}{l}\text { Repeatability of positioning } \\
\text { displacement bidirectional }\end{array}$ & $0.8 \mu \mathrm{m}$ \\
\hline Repeatability rotation & $150 \mu \mathrm{Rad}$ \\
\hline
\end{tabular}

Determining the individual axes is shown in Fig.7.

Axes $X, Y$, and $Z$ represent the basic spatial coordinate system where $X, Y$ represent movement on the desktop and the $\mathrm{Z}$ coordinate represents the height above the base surface. Furthermore, three motions can be controlled - rotation R1, R2, and R3.

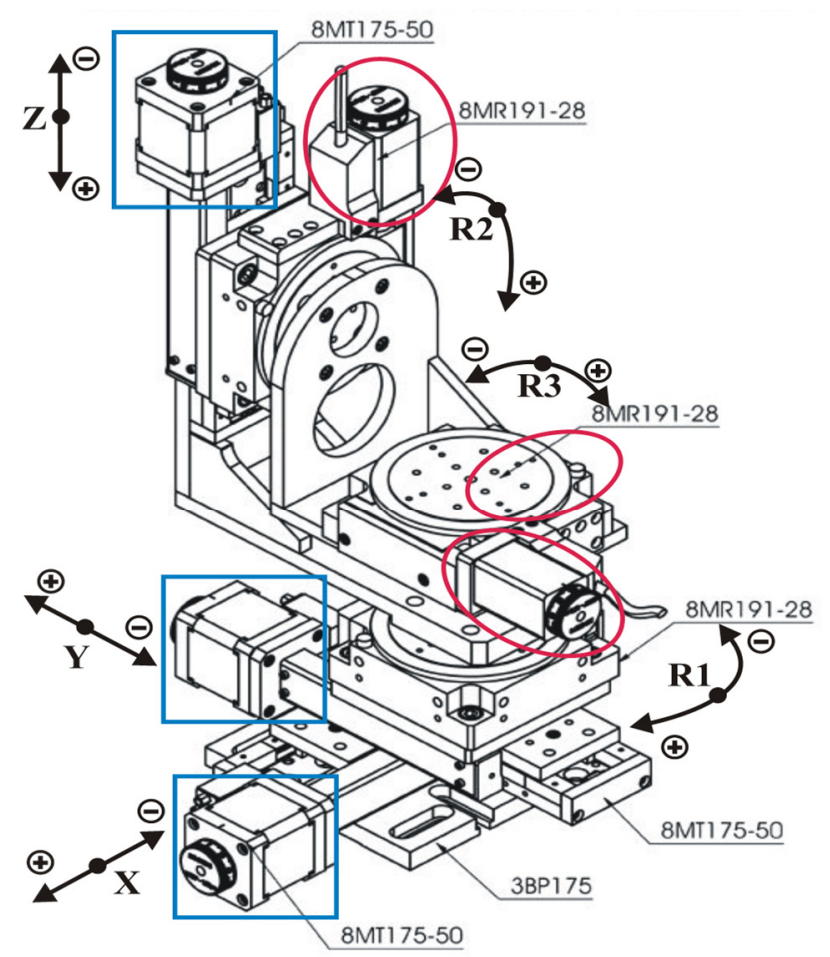

Fig.7. Positioner and determination of the individual axes drives.

\section{REALIZATION OF MEASURING WORKPLACE}

The total hardware concept of the actual measuring workstation is shown in Fig.8. [11]. Workplace consists of a radiation source 2 , wherein it is required that its emissivity is close to 1 , and there is the possibility to set the temperature. This radiation then goes through an aperture 4, where we can set up an area radiation source. Then it continues through a chopper 3, whose task is to interrupt the radiation flux to define the changes needed for the proper function of the pyroelement. Radiation then falls on its motion detector 6 , whose position can be precisely adjusted using the positioner 5 . 


\section{LIBRARIES OF PROGRAMS FOR THE CONTROL OF MOTORS}

For testing drives, the manipulator is equipped with a special program; its user interface is shown in Fig.9. This program can be used with advantage for the initial position of the manipulator. Linear drives have endpoints, from which you can then roll to a specific desired position. Also, rotating movements have their hardware starting position from which it can be moved in steps to a specific desired position [15], [16].
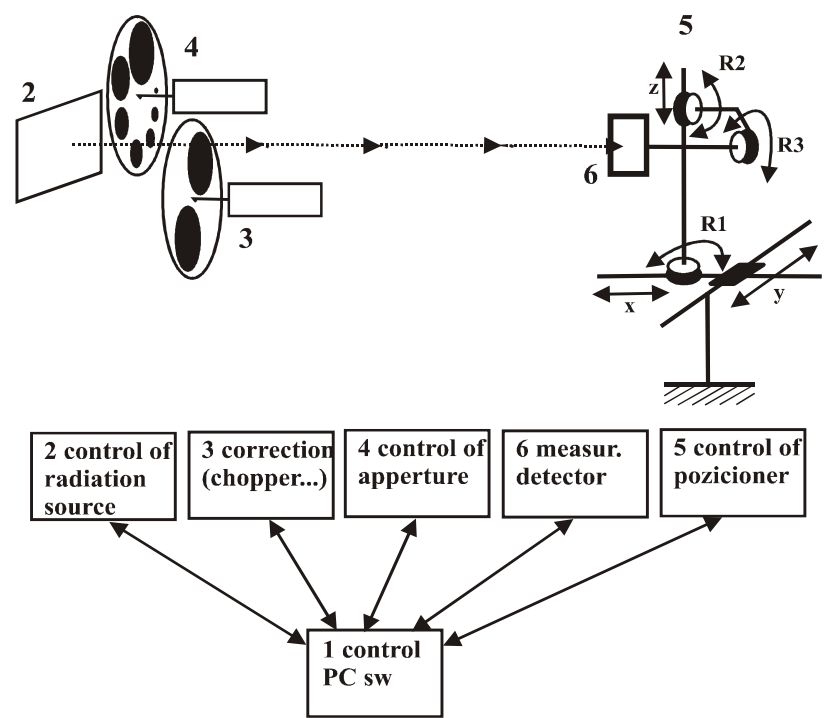

Fig.8. Hardware workplace concepts.

For further development of the control of the program, the program of the Development kit from the manufacturer of the manipulator has been recovered, that includes the drivers of drives and their calls using global variables. Their part shown in the LabView is shown in Fig.9. and Fig.11. as Default parameters and Run-Time parameters. The default parameters are used to set the default properties for the drive and Run-Time parameters command the control unit, thus the immediate control of the actuator [15], [17].

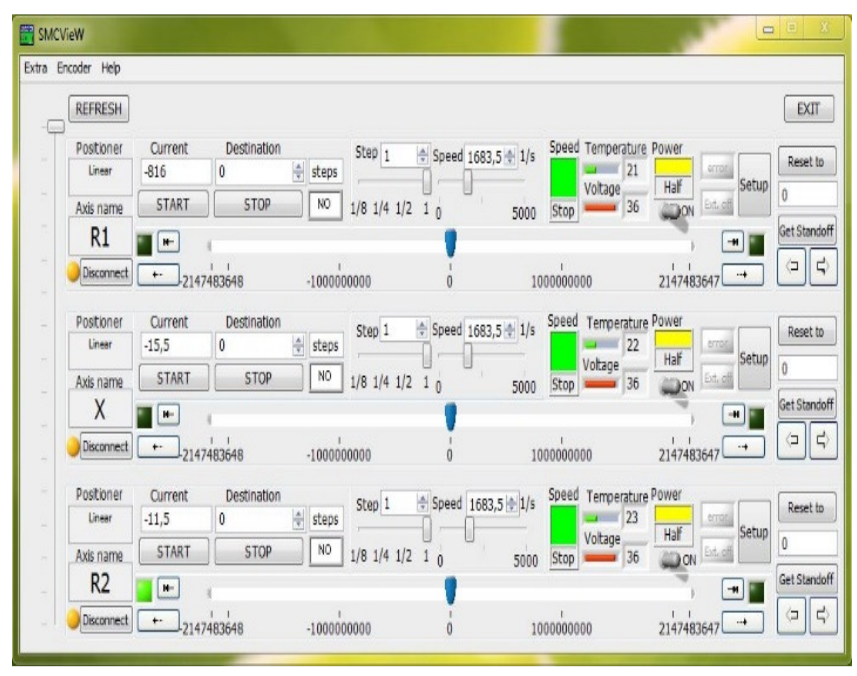

Fig.9. The geometric layout of the situation.

\section{PROGRAM For THE MEASUREMENT CONTROL}

Fig.10. shows a full simplified functionality. In Fig.11. is shown a specific user interface for the measurement of the PIR detector. After the start of the program, control values are initialized, which means setting all the Run-Time Default parameters from the default parameters. After starting step "Find Devices", physically connected drives are loaded. Button from the group "Movement" may serve to set the initial position of the manipulator to its initial position in the measurement device. It is then necessary to make "set range," set restrictive conditions for mechanical drives or other devices. After calling the "start measurement", measurement is started and at each position the measurement is performed, the values are stored in a database and simultaneously displayed on the chart. Then the next step is performed at a new position, and the measurement is repeated until reaching the limit position specified in step "set range", then the measurement is finished [18], [20].

From the graphs, it is evident that the heat treatment for 1-5 seconds for incident radiation having a density of $0.75 \mathrm{~W} / \mathrm{m}^{2}$ temperature of pyroelement increased about $0.015^{\circ} \mathrm{C}$, while for incident radiation having a density of $0.02 \mathrm{~W} / \mathrm{m}^{2}$, the temperature hardly increased the pyroelement.

The calculations and simulations, the temperature distribution in the heated pyroelement also show that even at low values of the density of heat flux at a given time, the surface temperature of pyroelement is nearly the same temperature throughout its thickness (no steep temperature field). This proves that the pyroelement is flawed. It can be said that in the early stages of measurement the pyroelement evaluates right temperature and laboratory measurements are therefore in the initial stages sufficiently accurate.

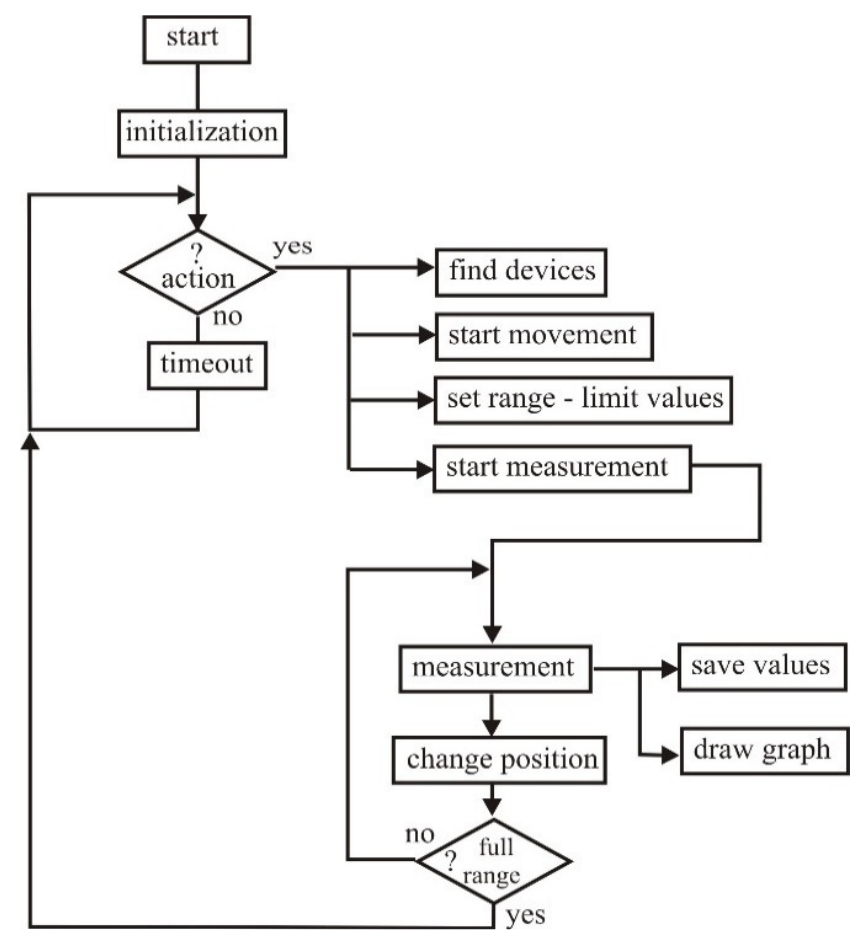

Fig.10. Simplified flowchart of the measurement program. 


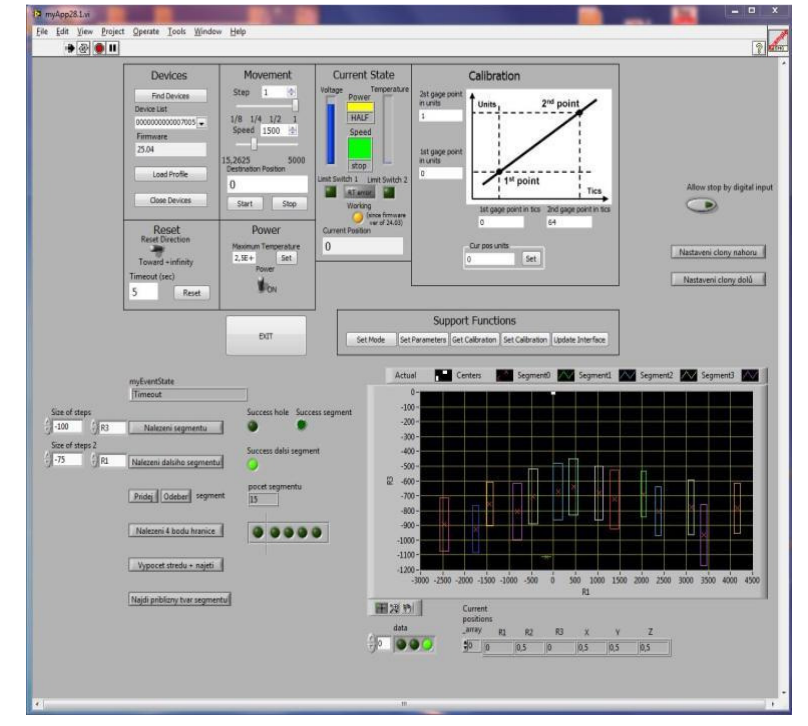

Fig.11. Sample application user interface for measurement of the PIR detector.

This measurement takes several hours, so it is advisable to fully automate the measurement process control. Measurement of the spatial characteristics of the various devices is a large problem measuring disturbances and also owns its electromagnetic radiation manipulator. This must be solved individually for a specific type of measurement. However, this problem occurs even when we use measurement for classical departments of large dimensions. However, these problems are much larger and shading the large space is more difficult.

\section{ACKNOWLEDGMENT}

This work was supported by the Ministry of Education, Youth and Sport of the Czech Republic within the National Sustainability Programme project No. LO1303 (MSMT7778/2014) and also by the European Regional Development Fund under the project CEBIA-Tech No.

CZ.1.05/2.1.00/03.0089.

The authors would like to thank the Slovak University of Technology in Bratislava, the Grant agency APVV (project number APVV-15-0164), the agency KEGA (project numbers KEGA 039STU-4/2017) for their support.

\section{REFERENCES}

[1] Vincent, J.D. (1990). Fundamentals of Infrared Detector Operation and Testing. Wiley-Interscience.

[2] Knoll, G.F. (2000). Radiation Detection and Measurement. Wiley.

[3] Saleh, B.E.A., Teich, M.C. (2007). Fundamentals of Photonics. Wiley-Interscience.

[4] Czech Office for Standards, Metrology and Testing. (2011). Alarm systems - CCTV surveillance systems for use in security applications Part 7: Application guidelines. CSN EN 50132.

[5] Czech Office for Standards, Metrology and Testing. (2002). Fire detection and fire alarm systems - Part 10: Flame detectors - Point detectors. CSN EN 54-10.
[6] Tyco Fire \& Security. (2008). Flame detector S300, datasheet.

[7] Tyco Fire \& Security. (2008). Flame detector S200, datasheet.

[8] Jha, A.R. (2000). Infrared Technology. WileyInterscience.

[9] Czech Office for Standards, Metrology and Testing. (2008). Alarm systems - Intrusion and hold-up systems - Part 2-2: Intrusion detectors - Passive infrared detectors. CSN 50131-2-2.

[10] Hotz, C. (1979). Přenos tepla zářením. Prague, Czech Republic: SNTL. (in Czech)

[11] Kolomazník, K. (1990). Modelování zpracovatelských procesů. Brno, Czech Republic: University of Technology in Brno. (in Czech)

[12] Feriančik, M., Líška, O., More, M. (2013). Navigation of industrial manipulator based on computer vision. Transfer inovácií, 28, 140-142.

[13] Drga, R., Janáčová, D. (2012). PIR detector measurement using thermal cameras. Strojárstvo extra, 2012, 281-286.

[14] Makovník, R., Liška, O. (2007). Contribution to experimental identification and simulation problems of dynamic systems. Ovidius University Annual Scientific Journal, 9 (1).

[15] Kastek, M., Madura, H., Morawski, M., Piatkowski, T., Powiada, E., Polakowski, H. (2007). Test bed for measurement of angular parameters of passive infrared sensors. Infrared Physics and Technology, 49 (3), 198201.

[16] Rafique, F., Siddiqui, N. (2013). Passive IR field gradient detection of thermal objects in active Fresnel zones. Infrared Physics and Technology, 60, 145-154.

[17] Úředníček, Z., Drga, R. (2016). Measuring robot kinematics description and its workspace. MATEC Web of Conferences, 76, 02027.

[18] Drga, R. (2012). Nepřesnosti při měření teploty zdroje IR záření termovizní kamerou. In Automatizácia a riadenie v teórii a praxi. Košice, Slovak Republic: Technical University of Košice, 19.1-19.8. (in Czech)

[19] Hart, J., Hartová, V., Bradna, J. (2016). Intrusion and hold-up alarm systems and their reliability glass break detection. In Proceeding of $6^{\text {th }}$ International Conference on Trends in Agricultural Engineering 2016. Prague, Czech Republic: Czech University of Life Sciences, 171-174.

[20] Miyazaki, T., Shinohara, F., Horiuchi, T., Ohira, Y., Yamamoto, H., Nishi, M. (2016). Health checking system using wearable health devise and PIR sensors. In Proceedings of the $2^{\text {nd }}$ International Conference on Sensors and Electronic Instrumentation Advances. IFSA Publishing, 85-86. 